\title{
The use of rationalization and denial to reduce accident-related and illness-related death anxiety
}

\author{
BETH S. GERSHUNY and DAVID BURROWS \\ Skidmore College, Saratoga Springs, New York
}

\begin{abstract}
Subjects read stories depicting the death of an individual through either an accident or a terminal illness. The subjects then answered questions designed to measure the extent to which various defense mechanisms were elicited by the stories. In Experiment 1, the subjects used rationalization more than denial or repression after reading the accident story, but they used all three defenses with equal magnitude after the illness story. In Experiment 2, rationalization was again used more than denial after the accident story, and the two defenses were used with similar magnitude after the illness story. There may be specific trauma-defense relationships whose existence depends on specific characteristics of both the type of trauma and the type of defense mechanism.
\end{abstract}

Our purpose in the present research was to examine the uses of denial, repression, and rationalization to relieve death anxiety. We were interested in determining whether there is one defense mechanism that is typically preferred as a means of dealing with the intense anxiety of death, and whether the pattern of defense-mechanism use is affected by the specific type of death trauma. The determination of which mechanisms are actually used in highly stressful situations has theoretical implications for the understanding of cognitive defense mechanisms, as well as practical implications for grief therapy.

Death anxiety is important, because we live in an age in which death is not easily acknowledged. Often, survivors do not understand or know how to deal with their feelings when someone dies (Stephenson, 1985). There have been relatively few attempts to measure exactly what coping strategies are used, despite the potential value of such measurements. Because different types of death may lead to different levels and types of stress (Florian, Kravetz, \& Frankel, 1984; Heilbrun \& Pepe, 1985; Pietropinto, 1985), different defenses may be used to cope with different types of death situations. Thus, a full understanding of trauma-defense relationships requires that one examine a variety of death situations and defense types.

In the present studies, we attempted to begin mapping the trauma-defense relationship by inducing death anxiety through stories of accident-caused or illness-caused death, and by measuring the subsequent extent of defensemechanism use on questionnaires.

\section{EXPERIMENT 1}

\section{Method}

Subjects. The subjects were 31 college undergraduates recruited from psychology classes. They had no prior knowledge of the nature of the

The authors wish to dedicate this paper to Isadora Landes Falk. Her life and love were the motivation for these studies. Requests for reprints should be sent to the first author at 12 Round Hill Rd., Poughkeepsie, NY 12603. experiment. Potential subjects who had experienced recent deaths in the immediate family were excused.

Procedure. Each subject read a story depicting a protagonist experiencing the death of a parent, either through terminal illness (cancer) or as the result of an unexpected (auto) accident. After reading the story, the subject filled out a questionnaire designed to measure general levels of death anxiety, and then a second questionnaire designed to measure defense-mechanism use. In the second questionnaire, 6 questions measured the use of rationalization (e.g., "To what extent is the parent better off dying?"), 6 measured denial (e.g., "How likely is it that anyone you know will ever die this way?"), and 6 measured repression (e.g., "How much suffering did the victim experience?"-when the details of the story made it clear that a great deal of suffering was encountered) Responses consisted of giving a rating between 1 and 7 . Some questions were worded so that higher ratings represented greater use of the defense probed by the question, whereas others were worded so that lower ratings signified greater use of the defense. The subjects' ratings were transformed to yield magnitude scores, with higher numbers indicating greater defense-mechanism use.

The subjects were randomly assigned to either the accident or the illness condition. Each was allowed $5 \mathrm{~min}$ to read the story, $10 \mathrm{~min}$ to complete the general levels of anxiety questionnaire, and $10 \mathrm{~min}$ to complete the defense-mechanism questionnaire.

\section{Results}

Figure 1 shows mean defense scores as a function of both type of trauma (accident or illness) and type of defense (rationalization, denial, or repression). A mean score for each defense mechanism was computed for each subject. The points on the figure represent means across subjects. Rationalization is used with greater magnitude than either denial or repression, with the latter two yielding almost identical scores. This pattern interacts strongly with type of trauma: The difference between rationalization and the other defenses is extremely large for the accident but almost nonexistent for the illness. A $2 \times 3$ analysis of variance showed a main effect for type of defense mechanism $[F(2,58)=54.8, p<.001]$ and an interaction between defense mechanism and trauma $[F(2,58)=46.2$, $p<.001]$. There was no effect of type of trauma $(F<1)$.

Correlational analyses showed a correlation between the magnitude of repression scores and magnitude of denial scores $[r(29)=.49, p<.01]$, as well as a negative corre- 


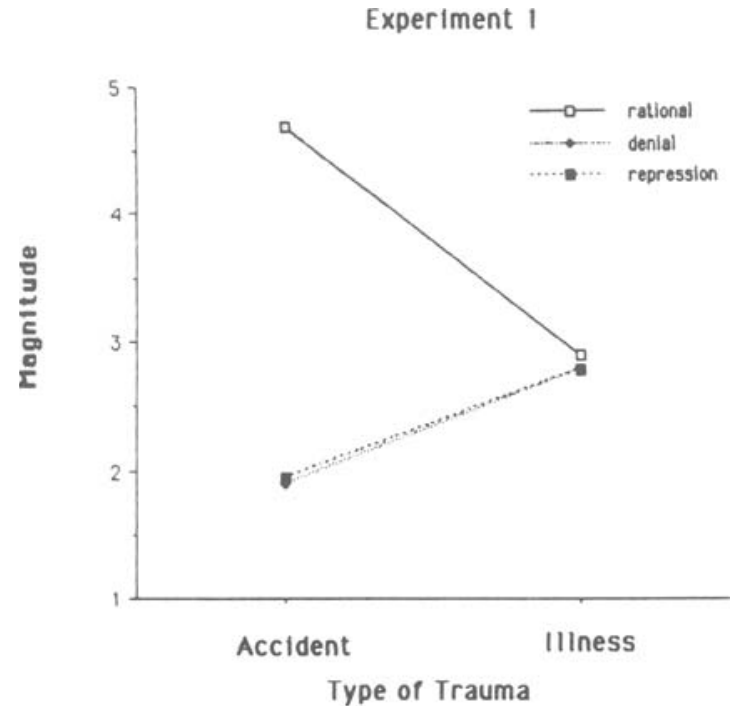

Figure 1. Magnitude of defense mechanism use as a function of type of trauma and type of defense mechanism: Experiment 1.

lation between magnitude of repression and magnitude of rationalization $[r(29)=-.36, p<.05]$.

\section{Discussion}

The results suggest some specific relationships between types of trauma and the types of defense mechanisms used to cope with such traumas. Rationalization is used to a much greater extent than denial or repression to cope with the accident story. For an illness, the three mechanisms are used to an extent that is virtually identical. This suggests that defense-mechanism use is specialized. Something about rationalization makes it more useful for accidental death, whereas the different mechanisms are roughly equivalent in their usefulness for dealing with the trauma of illness.

The results support earlier assertions that denial and repression are equivalent mechanisms (Gleser \& Ihilevich, 1969). The repression and denial magnitude scores are identical in the two trauma conditions and the use of those mechanisms is positively correlated.

\section{EXPERIMENT 2}

Experiment 2 was done to replicate Experiment 1, using an expanded and revised set of questions. Questions about repression were eliminated, under the assumption that repression could not be differentiated from denial, and questions about rationalization and denial were constructed and added instead.

\section{Method}

Subjects. The subjects were 8 students enrolled in a summer psychology course. None had recently experienced a death in the immediate family.

Procedure. Each subject read an accident story or a terminal illness story. Each subject then filled out a questionnaire containing questions about general anxiety, followed by a questionnaire measuring the subject's use of both rationalization and denial to cope with the accident or illness. This questionnaire had 20 questions, 10 for rationalization and 10 for denial. Each set of 10 consisted of the 6 used in Experiment 1, plus 4 new questions designed to measure the appropriate mechanism. The remaining procedures are identical to those in Experiment 1.

\section{Results}

Figure 2 shows mean magnitude of defense use as a function of trauma (accident or illness) and mechanism (rationalization or denial). Generally, rationalization is used to a greater extent than denial. The difference between rationalization and denial is quite large for the accident condition and much smaller in the illness condition. This pattern is similar to that in Experiment 1. A $2 \times 2$ analysis of variance yielded significant main effects for type of trauma $[F(1,6)=10.3, p<.02]$ and type of mechanism $[F(1,6)=33.8, p<.01]$, as well as a significant interaction between the two $[F(1,6)=11.9, p<.02]$.

\section{Discussion}

As in Experiment 1, it appears that defense mechanisms may be specialized; the extent to which a particular defense mechanism is used depends on the type of trauma that has been presented. Rationalization seems to be preferred to denial when one is confronting the death of a loved one through an accident, whereas the two are used to a similar extent in coping with the illness of a loved one. One difference between the two experiments is the finding of a main effect of trauma in Experiment 2; apparently the overall use of defense mechanisms was greater for the accident than for the illness. This may reflect the greater need for mechanisms in coping with an accident story. It may also occur because the best mechanisms for coping with an illness were not probed. Some other mechanism might have yielded higher scores for illness that would bring the overall scores to an equivalent level.

A complete understanding of the trauma-defense relationship will require further study. First, different types of traumas need to be researched. Traumas differ on several dimensions, such as suddenness of death or amount of pain suffered by the victim, and the role of these characteristics needs to be investigated. A wider variety of defense mechanisms might also be tested. The reasons for the increased use of a particular defense mechanism in a particular situation need to be understood.

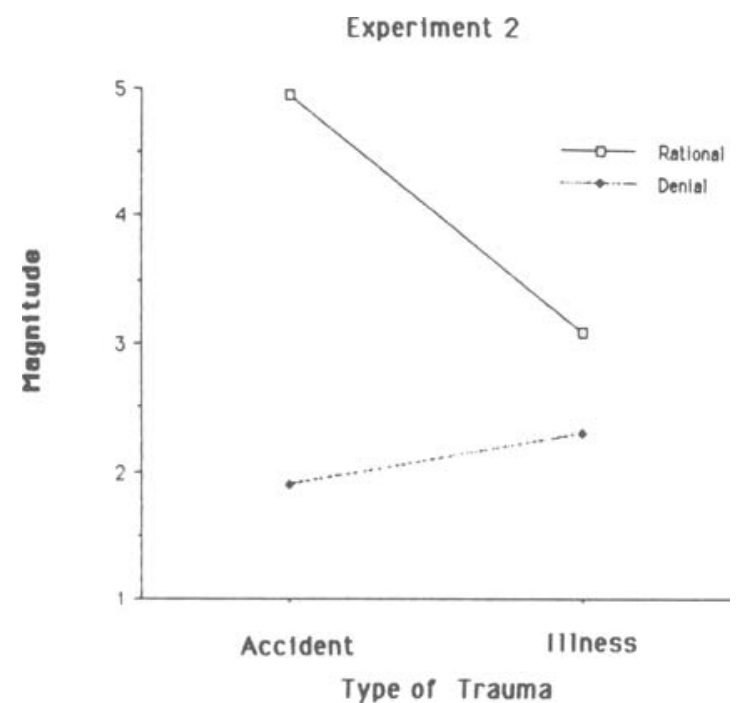

Figure 2. Magnitude of defense mechanism use as a function of type of trauma and type of defense mechanism: Experiment 2. 
Rationalization may be preferred because it is a more "intellectualized" mechanism than denial, for example, but this hypothesis was not tested in the present studies. These issues await further research.

\section{REFERENCES}

Florian, V., Kravetz, S., \& Frankel, J. (1984). Aspects of fear of personal death, levels of awareness, and religious commitment. Journal of Research in Personality, 18, 289-304.

Gleser, G. C., \& IHILEvich, D. (1969). An objective instrument for measuring defense mechanisms. Journal of Consulting \& Clinical Psychology, 33, 51-60.
Heilbrun, A. B., \& Pepe, V. (1985). Awareness of cognitive defenses and stress management. British Journal of Medical Psychology, 58, 9-17.

Pietropinto, A. (1985). Coping with death in the family. Medical Aspects of Human Sexuality, 19, 76-82.

STEPHENSON, J. S. (1985). Death and the campus community: Organizational realities and personal tragedies. In E. S. Zinner (Ed.), Coping with death on campus: New directions for student services (pp. 5-13). San Francisco: Jossey-Bass.

(Manuscript received August 3, 1989.) 